\title{
Macular hole formation in a patient with Irvine- Gass syndrome: coincidence or rare complication?
}

This article was published in the following Dove Press journal:

Clinical Ophthalmology

12 July 2013

Number of times this article has been viewed

\author{
Marilita M Moschos' \\ Zisis Gatzioufas² \\ Tryfon Rotsos' \\ Chrysanthos Symeonidis ${ }^{3}$ \\ Xuefei Song ${ }^{2}$ \\ Berthold Seitz ${ }^{2}$ \\ 'Ist Department of Ophthalmology, \\ University of Athens, Athens, Greece; \\ ${ }^{2}$ Department of Ophthalmology, \\ University of Saarland, Homburg/ \\ Saar, Germany; ${ }^{3} 2$ nd Department of \\ Ophthalmology, Aristotle University \\ of Thessaloniki, Thessaloniki, \\ Macedonia, Greece
}

Background: Macular edema (ME) is caused by abnormal retinal capillary permeability and has also been described as a postoperative complication of cataract surgery (Irvine-Gass syndrome).

Objective: To present a patient with Irvine-Gass syndrome in the right eye complicated with a macular hole $(\mathrm{MH})$ in the same eye and possible associations between these two entities.

Case report: A 72-year-old male with a history of uneventful bilateral cataract surgery was followed-up with biomicroscopy and optical coherence tomography (OCT). Four weeks after cataract surgery oculus dexter (OD), there was progressive visual deterioration (best corrected visual acuity [BCVA]: 0.5). OCT disclosed cystoid ME. A parabulbar triamcinolone injection, dexamethasone $0.1 \%$ and ketorolac $0.4 \%$ eye drops, both 4 times per day OD were administered. Six weeks later (BCVA OD: 0.2), OCT revealed cystoid ME and full-thickness MH.

Conclusion: ME secondary to diabetes or central retinal vein occlusion may lead to $\mathrm{MH}$ by inducing focal vitreomacular traction and by triggering inflammatory mechanisms which facilitate a marked thinning of the fovea. MH may occur even in cases of pseudophakic ME, representing a rare complication of Irvine-Gass syndrome.

Keywords: Irvine-Gass syndrome, macular hole, macular edema

\section{Introduction}

Macular edema (ME) is thought to be caused by abnormal retinal capillary permeability. The resulting leakage has a detrimental effect on central retinal function, characterized by a varying decrease in visual acuity. ${ }^{1} \mathrm{ME}$ has been linked to diabetic retinopathy, retinal vein occlusion, and uveitis, while it has also been described as a postoperative complication of cataract extraction surgery (Irvine-Gass syndrome). ${ }^{2}$ In this disorder, cystoid $\mathrm{ME}(\mathrm{CME})$ is observed and characterized by petalloid perifoveal leakage on fluorescein angiography.

A classification system focusing on anteroposterior and tangential vitreal traction on the foveal area as a principal cause for idiopathic macular holes (MHs) was proposed by Gass. ${ }^{1}$ These tractional forces have been postulated to induce foveolar dehiscence, which facilitates hydration of middle and outer retinal layers, leading to edema and cell displacement. ${ }^{3}$ Moreover, persistent vitreous adherence to the fovea coupled with shrinkage of prefoveal vitreous results in the causative traction. We present a patient with Irvine-Gass syndrome in the right eye complicated with an $\mathrm{MH}$ in the same eye and possible associations between these two entities.
Correspondence: Tryfon Rotsos Ist Department of Ophthalmology, University of Athens, G Genimatas Hospital, I54 Mesogeion Ave, I I 527 Athens, Greece

Tel +30697472 7279

Email tryfonrotsos@hotmail.com 


\section{Case report}

A 72-year-old male patient underwent uneventful cataract surgery in the left eye (oculus sinister [OS]) in May 2009 and in the right eye (oculus dexter [OD]) in November 2009. No retinal pathology was present before surgery and the patient did not suffer from any systemic condition that may affect the retina. Best corrected visual acuity (BCVA) in both eyes (oculus uterque [OU]) was 1.01 week after each cataract extraction procedure. Four weeks following cataract surgery $\mathrm{OD}$, the patient presented with progressive visual deterioration OD (BCVA OD: 0.5). Slit lamp examination did not reveal pathological findings OU; the intraocular lens (IOL) was symmetrically positioned in the capsular bag with no signs of capsule opacification. Optical coherence tomography (OCT) scans revealed CME (Figure 1A).
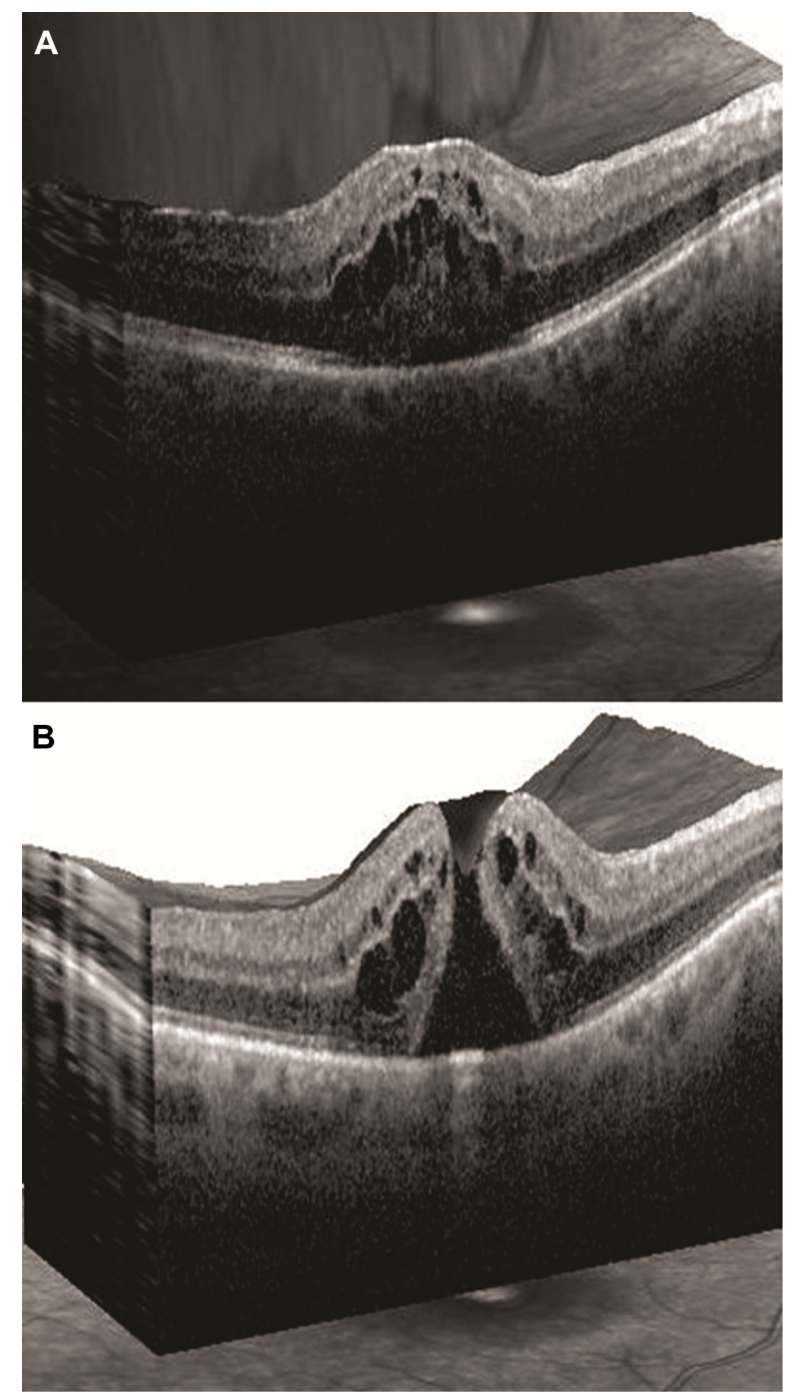

Figure I (A) Patient OCT scan depicting cystoid macular edema. (B) Patient OCT scan depicting cystoid macular edema and full-thickness macular hole (Grade IV). Abbreviation: OCT, optical coherence tomography.
No findings were observed OS. A parabulbar triamcinolone injection, dexamethasone $0.1 \%$ and ketorolac tromethamine $0.4 \%$ eye drops ( 4 times daily) were administered OD. Six weeks later (BCVA OD: 0.2), OCT scans revealed CME and a full-thickness MH (Figure 1B). Intravitreal bevacizumab administration and vitrectomy with internal limiting membrane peeling were discussed but the patient refused further management.

\section{Discussion}

ME development depends on the associated disease with the common feature being the blood-retina barrier breakdown. During this process, Müller cells become swollen and are eventually lysed. This results in extracellular fluid accumulation in the outer plexiform and inner nuclear layers. Consequently, ME can be caused directly, due to endothelial cell damage, as it occurs in the context of diabetes mellitus and retinal vein occlusion and may lead to $\mathrm{MH}$ development. ${ }^{4}$ MH formation may be induced by macular traction in combination with retinochoroidal atrophy in the context of recurring inflammation. ${ }^{5}$

Full-thickness MH formation can be observed as early as 2 days following uncomplicated phacoemulsification. ${ }^{6}$ In our case, CME was present 4 weeks postoperatively. It is conceivable that $\mathrm{MH}$ formation was initiated either by the conduction of phacoemulsification mechanical forces intraoperatively or by biochemical alterations postoperatively that resulted in localized vitreous liquefaction and subsequently traction. In this context, a sensible surgical strategy would be the intraoperative minimization of anterior chamber depth and capsular bag fluctuations with the use of relatively constant irrigation and aspiration settings. This could possibly result in reduced zonule damage during phacoemulsification and reduced conduction and application of mechanical forces to the macular area. Our case report suggests that MH formation may even occur in cases of pseudophakic ME, representing a rare complication of Irvine-Gass syndrome.

\section{Disclosure}

The authors report no conflicts of interest in this work.

\section{References}

1. Gass JD. Idiopathic senile macular hole: its early stages and pathogenesis. 1988. Retina. 2003;23(Suppl 6):629-639.

2. Kuppermann BD, Blumenkranz MS, Haller JA, et al; Dexamethasone DDS Phase II Study Group. Randomized controlled study of an intravitreous dexamethasone drug delivery system in patients with persistent macular edema. Arch Ophthalmol. 2007;125(3):309-317.

3. Tornambe PE. Macular hole genesis: the hydration theory. Retina. 2003;23(3):421-424. 
4. Unoki N, Nishijima K, Kita M, et al. Lamellar macular hole formation in patients with diabetic cystoid macular edema. Retina. 2009;29(8):1128-1133.

5. Georgalas I, Markomichelakis N, Ladas I. Retinal detachment due to a macular hole in a patient with Behcet disease treated with vitrectomy and silicone oil tamponade. Eur J Ophthalmol. 2008;18(6):1023-1024.
6. Patterson JA, Ezra E, Gregor ZJ. Acute full-thickness macular hole after uncomplicated phacoemulsification cataract surgery. Am J Ophthalmol. 2001;131(6):799-800.

\section{Publish your work in this journal}

Clinical Ophthalmology is an international, peer-reviewed journal covering all subspecialties within ophthalmology. Key topics include: Optometry; Visual science; Pharmacology and drug therapy in eye diseases; Basic Sciences; Primary and Secondary eye care; Patien Safety and Quality of Care Improvements. This journal is indexed on

Submit your manuscript here: http://www.dovepress.com/clinical-ophthalmology-journal

\section{Dovepress}

PubMed Central and CAS, and is the official journal of The Society of Clinical Ophthalmology (SCO). The manuscript management system is completely online and includes a very quick and fair peer-review system, which is all easy to use. Visit http://www.dovepress.com/ testimonials.php to read real quotes from published authors. 